\title{
A Socioeconomic-Based Analysis of Disaster Preparedness, Awareness and Education
}

\author{
Ronik Ketankumar Patel ${ }^{1}$, Sharareh Kermanshachi ${ }^{2}$ and Mostafa Namian ${ }^{3}$
}

1 University of Texas at Arlington, Arlington, USA, ronikketankumar.patel@mavs.uta.edu

2 University of Texas at Arlington, Arlington, USA, sharareh.kermanshachi@uta.edu

3 East Carolina University, Greenville, USA, namianm19@ecu.edu

\begin{abstract}
Students are one of the most vulnerable subgroups of the general population in terms of disaster preparedness and response; however, many universities still lack strategies and planning for disaster preparedness, mitigation, and response. This study investigated students' perceptions of disaster awareness and preparedness, based on two demographic characteristics: where they lived (on campus or off campus) and their ethnicity. To carry out this research, a comprehensive literature review was conducted on disaster education. Next, a structured survey was developed based on the factors studied in the literature review, and it was distributed to university students above the age of 18 with the help of an online assessment tool, Qualtrics. A total of 111 responses to the survey were collected, and the data collected were analyzed by performing descriptive and statistical analyses. After conducting the analyses, it was found that the perspectives of the students living on campus towards disaster risk reduction (DRR) education was significantly different from those living off campus. There were similar distinct differences linked to their area of living and ethnic backgrounds. It was further revealed that based on both their location and ethnic background, students have very different perspectives on the role of their friends, parents, and the university in keeping them safe during a disaster. The findings of this study will help policymakers assess existing disaster preparedness programs and will help faculty members and the academic staff develop and implement effective disaster preparedness courses and drills at the university, based on the characteristics of the students.
\end{abstract}

(c) 2020 The Authors. Published by Budapest University of Technology and Economics \& Diamond Congress Ltd Peer-review under responsibility of the Scientific Committee of the Creative Construction Conference 2020.

Keywords: disaster education, students' disaster preparedness, students' perception, disaster awareness

\section{Introduction}

Every year disasters are responsible for major economic losses [1], damage to properties [2], and extensive loss of life [3,4,5]. Disasters were responsible for the loss of eight [6] million lives and economic losses of 700 trillion dollars from 1990 to 2015 [7]. In recent years, universities have been affected by many disasters that have disrupted classes and damaged school buildings. Many kinds of research have been done on disaster risk reduction [8] because of the extensive damage and disruptions caused by them $[9,10,11,12,13$ ] and other efforts have been made to increase disaster preparedness among the general community $[14,15,16,17]$. One study discussed the recent disasters that have affected universities [18], and a study by Tanner and Doberstein evaluated students' disaster preparedness by considering their inventory of emergency supplies [19]. Students are vulnerable to disasters both at their home and at the university [20], but few educational institutions have recognized the importance of making disaster preparedness education available to students [21]. Consequently, effective disaster prevention, mitigation, and preparedness strategies are still lacking. The primary aim of this study was to analyse and evaluate 
students' perceptions of disaster awareness, preparedness, and education based on two demographic characteristics (i.e., ethnicity and location). To conduct this research, a comprehensive literature review was conducted of disaster-education-related factors. Next, a structured survey was developed with the help of an online survey tool, Qualtrics. The survey was distributed to students more than 18 years old, and a total of 111 responses were collected. The results were interpreted after performing descriptive and statistical analyses of the collected data. The findings of this study will provide policymakers with better insights on how to update or develop effective disaster preparedness programs in the university.

\section{Literature review}

A disaster is a condition that causes an interruption in the effective functioning of society [22], including individuals, materials, economic losses [23], and impacts [24], that surpass the level at which society can cope $[25,26]$. The United States has been affected by more than 10,000 mild and severe disasters in the past century [27]. Hurricane Katrina (New Orleans 2005) was among the disasters that impacted universities and was responsible for the loss of billions of dollars caused by damage to buildings, tuition loss, and declined enrolment [28]. Hurricane Harvey (Houston, 2017) and Hurricane Sandy (New York, 2012) were responsible for extensive loss of life [7]. Hurricane Mathew (North Carolina, 2016) affected five universities that were besieged by flooding, damage to buildings, and power outages that resulted in the campuses being shut for a week [19]. The coronavirus (Covid-19) pandemic is the most recent disaster that has caused disruptions to colleges and universities by leading to cancelation of in-person classes and providing onlineonly instructions all over the United States [29]. According to United Nations Educational, Scientific and Cultural Organization (UNESCO), the Covid-19 pandemic has impacted about $60 \%$ of the world's student population from pre-primary to tertiary education levels [30].

Natural disasters like earthquakes and hurricanes put students in difficult positions by disrupting their classes and damaging the school buildings [18]. They often damage the library buildings, cause the loss of administrative data, destroy the communication system, and inflict injuries upon the students and academic staff [18]. Despite the fact that students are one of the most vulnerable subgroups in the community to disasters, they are one of the most ignored ones [19]. A study by Nahayo et al. indicated that government entities are focused on engaging with the community in general and not specifically with the student population [7]. University students are a rare group of people with a flexible outlook and a unique ability to adapt to challenging situations [6]. Having these qualities allows them to learn disaster skills more quickly and effectively than the general population. A study in China suggested that available disaster courses are not currently meeting the students' needs [6]. As training sessions could significantly reduce the costs of the damages [31,32] and students can be useful resources for the community in general for disaster response, prevention, and mitigation, it is highly recommended to provide students proper training and education [20].

Universities are beginning to recognize the importance of being prepared for disasters [18]. Many studies have been conducted to assess students' emergency preparedness and describe the barriers that they face during a disaster [33]. A study conducted at the University of Texas studied students' perceptions of evacuation during a disaster and of returning to normalcy [34]. They found that international students face extreme difficulties during disasters, with lack of access to resources, and suggested that special consideration should be given to them during emergency preparedness and planning. A further study at the University of Waterloo revealed that a vast majority of students believed that they were responsible for their own safety during the first 72 hours of the disaster, while most of them did not have the required emergency preparedness kits or medical supplies [19]. Results of a previous study conducted in China suggested that universities should be provided with an effective and comprehensive disaster education course [6]. A similar study conducted in Indonesia discussed facilitators and deterrents for teachers to implement disaster risk reduction (DRR) education in their classes [35]. Therefore, insight into students' perspectives on disaster preparedness education is vital to developing an effective disaster risk reduction course and understanding their perspectives on disaster preparedness policies and procedures will lead to a better understanding of the effectiveness of the existing disaster preparedness programs [28]. 
Reviewing the previous literature reveals that little is known about students' disaster preparedness and the barriers faced by them during a disaster. Very few studies have been done in the context of how demographic characteristics affect students' perceptions of disaster preparedness; consequently, the basis of this research was to analyse and evaluate students' perceptions of disaster preparedness based on the demographic characteristics of students at the University of Texas at Arlington (USA). The focus of this study was limited to two demographics: ethnic background and whether they lived on campus or off-campus.

\section{Research methodology}

A four-step approach was adopted to fulfil the objective of this study (see Figure 1). An extensive literature review was conducted to study various disaster-related factors such as the importance of disaster education, the impacts of disasters on educational institutions, and the importance of disaster risk reduction education. In the second step, a structured survey was developed based on various disasterrelated parameters studied in the literature review. The survey was developed and distributed with the help of an online tool, Qualtrics. The invitations to participate were sent via email including a short description of the study. A total of 111 responses were collected, and in the third step, the collected data were analysed by performing descriptive and statistical analyses. As the collected data were in the 7 points Likert-scale format, the Kruskal Wallis test was performed to interpret the significance of students' perceptions based on two demographic characteristics (location and ethnicity). In the last step, results were interpreted and discussed in detail.

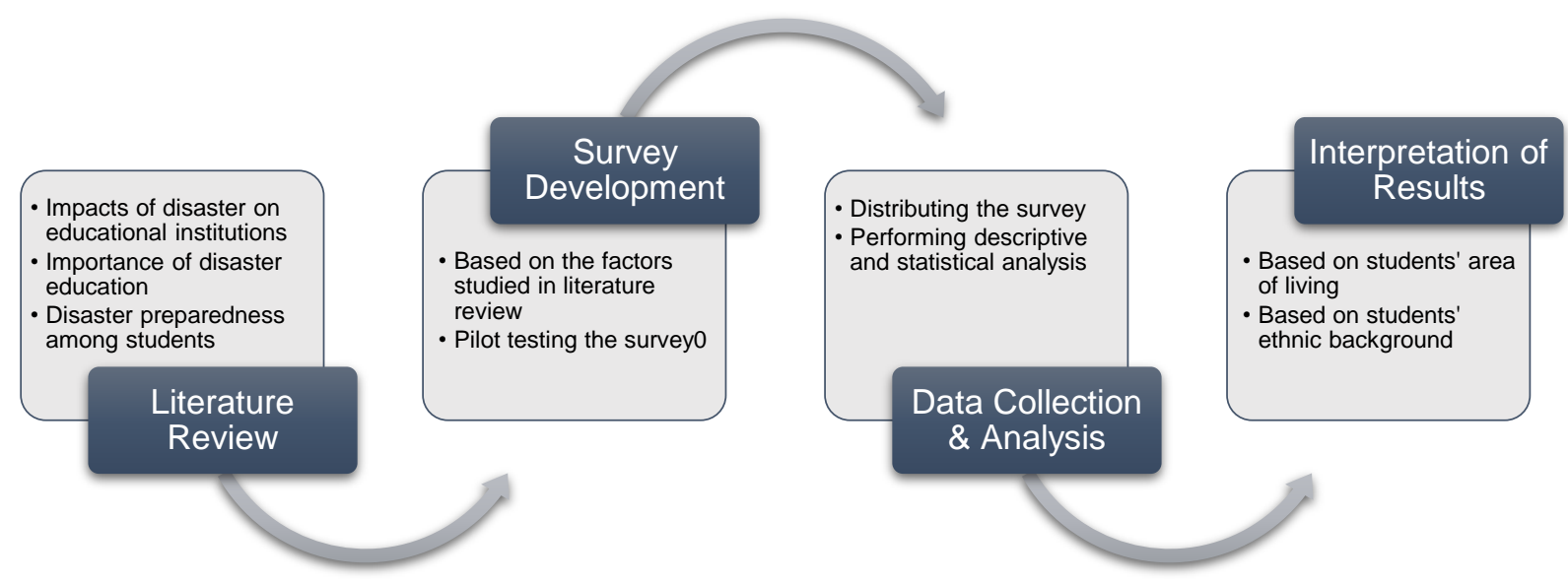

Figure 1. Research Methodology

Kruskal-Wallis test: The Kruskal Wallis test is a non-parametric test used to determine the difference between the observed average and the expected average of a data set. It is used to analyse data of two or more independent groups with an equal or different sample size that does not follow a normal distribution. It was adopted for this study as it is most suitable for analysing Likert scale data. The hypothesis developed for this study is shown in Table 1.

The equation used in the Kruskal Wallis test is provided below:

$$
H=\frac{12}{N(N+1)} \sum_{i=1}^{a} \frac{R_{i}^{2}}{n_{i}}-3(N-1)
$$

Here, $(R)$ indicates the rank of the individual group, $(N)$ represents the total number of observations, (a) represents the number of groups $\left(n_{i}\right)$ indicates the number of observations in group (i) [36]. 
Table 1. Hypotheses adopted for this study

\begin{tabular}{|c|c|c|}
\hline $\begin{array}{c}\text { Students' } \\
\text { characteristics }\end{array}$ & Statistical test & Hypotheses \\
\hline $\begin{array}{l}\text { Students' Living On- } \\
\text { Campus and Off- } \\
\text { Campus }\end{array}$ & $\begin{array}{c}\text { Kruskal-Wallis } \\
\text { test }\end{array}$ & $\begin{array}{l}\text { Null Hypothesis }\left(\mathrm{H}_{0}\right) \text { : Students living on campus and off-campus } \\
\text { have the same perception regarding disaster preparedness and } \\
\text { DRR education. } \\
\text { Alternative Hypothesis }\left(\mathrm{H}_{\mathrm{a}}\right) \text { : Students living on campus and off- } \\
\text { campus have different perceptions regarding disaster } \\
\text { preparedness and DRR education. }\end{array}$ \\
\hline $\begin{array}{c}\text { Asian and Non-Asian } \\
\text { Students }\end{array}$ & $\begin{array}{c}\text { Kruskal-Wallis } \\
\text { test }\end{array}$ & $\begin{array}{l}\text { Null Hypothesis }\left(\mathrm{H}_{0}\right) \text { : Asian and non-Asian students have the } \\
\text { same perceptions regarding disaster preparedness and DRR } \\
\text { education. } \\
\text { Alternative Hypothesis }\left(\mathrm{H}_{\mathrm{a}}\right) \text { : Asian and non-Asian students have } \\
\text { different perceptions regarding disaster preparedness and DRR } \\
\text { education. }\end{array}$ \\
\hline
\end{tabular}

\section{Data collection and analysis}

A comprehensive survey was developed based on the factors related to disaster education. The survey was developed and distributed with the help of an online data collection tool, Qualtrics. Pilot testing of the survey was conducted with the help of some doctoral students to check the clarity of questions before distributing it to the participants. The survey questionnaire was reviewed and approved by Institutional Review Board at the University of Texas at Arlington. The students enrolled at the University of Texas at Arlington and above the age of 18 years were chosen as the targeted population for this study. An invitation email was sent to the students with a brief description of the study. Electronic consent was obtained from the students at the beginning of the survey questionnaire. No compensation was provided to the students for participation in the study. A total of 111 responses were collected from students with different majors and levels of education. The survey questionnaire consisted of 45 questions in the form of Likert-scale and multiple-choice questions. The structure of the survey consisted of six sections with various questions regarding 1) demographics, 2) disaster experience, 3) disaster education, 4) emergency awareness, 5) university emergency procedures, and 6) implementation of disaster risk reduction (DRR) education, as shown in Figure 2. 


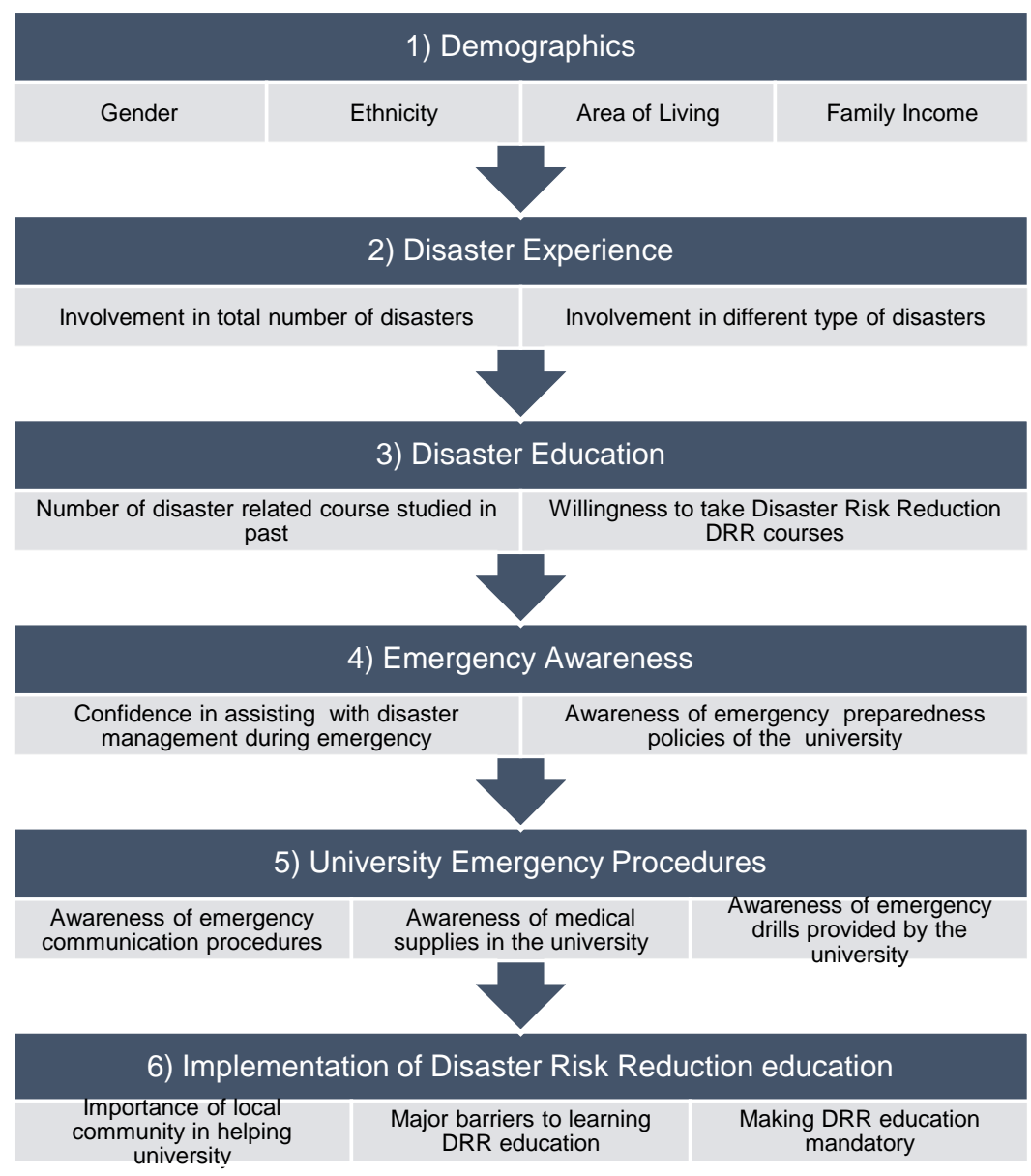

Figure 2. Structure of survey questionnaire

\subsection{Descriptive analysis}

The collected data revealed that of the 111 responses collected from the students, $78 \%$ of them were males, $22 \%$ females. Approximately $70 \%$ of the students lived off-campus and $30 \%$ lived on campus. Furthermore, analysing students' involvement in different types of disasters, it was found that the majority of the students had been involved in disasters such as earthquakes (25\%), thunderstorms (23\%), flooding (20\%), tornadoes (13\%), and hurricanes (5\%), while almost half of them (45\%) had not been involved in any type of disaster. An interesting finding suggested that the majority of the students' population (almost 74\%) had not had any disaster-related education. A detailed descriptive analysis of the collected data is provided in Table 2.

Table 2. Demographic information of student participants in the survey

\begin{tabular}{lll}
\hline Demographic Characteristics & Number in Sample & Percentage in Sample \\
\hline Gender & 87 & $78 \%$ \\
\hline Male & 24 & $22 \%$ \\
Female & & \\
\hline Ethnicity & 0 & $0 \%$ \\
\hline Native American & 7 & $7 \%$ \\
African American & 0 & $0 \%$ \\
American Indian or Alaskan Native & 68 & $65 \%$ \\
Asian & 12 & $11 \%$ \\
Hispanic & 0 & $0 \%$ \\
Native Hawaiian or Pacific Islander & &
\end{tabular}




\begin{tabular}{|c|c|c|}
\hline \multicolumn{3}{|c|}{ Level of Education } \\
\hline Freshman & 1 & $1 \%$ \\
\hline Sophomore & 6 & $5 \%$ \\
\hline Junior & 27 & $24 \%$ \\
\hline Senior & 5 & $5 \%$ \\
\hline Masters & 66 & $59 \%$ \\
\hline Ph.D. & 6 & $5 \%$ \\
\hline \multicolumn{3}{|c|}{ Student's Area of Living } \\
\hline Off Campus & 78 & $70 \%$ \\
\hline On-Campus & 33 & $30 \%$ \\
\hline \multicolumn{3}{|c|}{ Involvement in Disasters } \\
\hline Hurricane & 6 & $5 \%$ \\
\hline Tornado & 14 & $13 \%$ \\
\hline Flooding & 22 & $20 \%$ \\
\hline Thunderstorm & 25 & $23 \%$ \\
\hline Earthquake & 28 & $25 \%$ \\
\hline Tsunami & 3 & $3 \%$ \\
\hline None & 50 & $45 \%$ \\
\hline \multicolumn{3}{|c|}{ Involvement in Number of Disasters } \\
\hline $0-1$ & 69 & $63 \%$ \\
\hline $1-2$ & 13 & $12 \%$ \\
\hline $2-3$ & 16 & $15 \%$ \\
\hline $3-4$ & 3 & $3 \%$ \\
\hline $4-5$ & 2 & $2 \%$ \\
\hline More than 5 & 7 & $6 \%$ \\
\hline \multicolumn{3}{|c|}{ Disaster-related courses taken prior to university } \\
\hline $0-1$ & 81 & $74 \%$ \\
\hline $1-2$ & 22 & $20 \%$ \\
\hline $2-3$ & 4 & $4 \%$ \\
\hline $3-4$ & 1 & $1 \%$ \\
\hline $4-5$ & 0 & $0 \%$ \\
\hline More than 5 & 1 & $1 \%$ \\
\hline
\end{tabular}

\subsection{Statistical analysis}

To analyse the Likert scale data in the questionnaire, the Kruskal Wallis test was performed with the confidence level of 95\% (P-Value $\leq 0.05$ ) and 90\% (P-Value $\leq 0.1$ ). Table 3 indicates the P-Values based on the Kruskal Wallis test's results pertaining to the significance of students' perceptions of various types of disaster preparedness and disaster risk reduction (DRR) education parameters. A total of 22 parameters were tested based on two different demographic factors: 1) students living on campus and off-campus, and 
2) Asian and non-Asian students. The results suggested that seven (7) variables tested significant based on where the students lived, and eight (8) variables tested significant based on ethnicity, as shown in Table 3.

Table 3. P-Values testing the significance of students' perceptions of disaster preparedness and DRR education

\begin{tabular}{|c|c|c|c|}
\hline$\#$ & Variables & $\begin{array}{l}\text { P-Values for } \\
\text { Students living } \\
\text { On-Campus \& } \\
\text { Off-Campus }\end{array}$ & $\begin{array}{l}\text { P-Values for } \\
\text { Asian \& Non- } \\
\text { Asian } \\
\text { Students }\end{array}$ \\
\hline 1 & Willingness to take DRR course & $0.090^{* *}$ & 0.804 \\
\hline 2 & Confidence to assist with disaster management during emergency & 0.615 & 0.471 \\
\hline 3 & Confidence in providing basic first aid & 0.534 & 0.230 \\
\hline 4 & Curriculum provides psychological first aid training & 0.834 & 0.133 \\
\hline 5 & University has enough first aid boxes & 0.280 & $0.002^{*}$ \\
\hline 6 & Importance of local communities to help university & 0.763 & 0.406 \\
\hline 7 & Impact of severe natural disaster on student's life & $0.084^{* *}$ & 0.304 \\
\hline 8 & Students are responsible for their own safety & 0.555 & $0.060^{* *}$ \\
\hline 9 & Friends are responsible for students' safety & $0.037^{*}$ & $0.037^{*}$ \\
\hline 10 & Parents are responsible for students' safety & $0.084^{* *}$ & $0.018^{*}$ \\
\hline 11 & University is responsible for students' safety & $0.027^{*}$ & $0.018^{*}$ \\
\hline 12 & Government agencies are responsible for students' safety & 0.403 & 0.137 \\
\hline 13 & Awareness of the emergency procedures at the university & 0.450 & 0.124 \\
\hline 14 & Awareness of communication system provided by university during emergency & 0.771 & 0.438 \\
\hline 15 & University has online database regarding disaster preparedness & 0.542 & 0.505 \\
\hline 16 & Curriculum or disaster drill includes knowledge of disaster medicine & $0.020^{*}$ & $0.021^{*}$ \\
\hline 17 & University buildings have disaster shelters & 0.805 & 0.615 \\
\hline 18 & University includes students' guardians while providing disaster education & 0.433 & $0.091^{* *}$ \\
\hline 19 & Open to collaborating while handling a disaster & 0.754 & 0.184 \\
\hline 20 & Importance of local communities on helping university to implement DRR courses & $0.095^{\star *}$ & 0.551 \\
\hline 21 & DRR education should be made mandatory & $0.017^{*}$ & $0.019^{*}$ \\
\hline 22 & Likelihood of giving a test based on DRR education & $0.068^{* *}$ & $0.047^{\star}$ \\
\hline
\end{tabular}

Note: * Indicates $95 \%$ Level of Confidence

** Indicates $90 \%$ Level of Confidence

\section{Results and discussion}

\subsection{Analysis of students' perception of disaster preparedness and education: Students living on campus and off-campus}

The results, obtained by performing the statistical analysis (Kruskal Wallis test), revealed that the students' perceptions of the impact of natural disasters on their lives were different whether they lived on campus or off-campus. The P-Values in Table 3 indicate that students living on-campus and students living offcampus also have very different perspectives of the roles that their friends, parents, and the university play in their safety during a disaster. They had similar opinions, however, on the role of governmental agencies in students' safety during a disaster. Based on their area of living, students have different perspectives of taking DRR courses and being tested on the content, as well as different perspectives on mandatory DRR education. Students who lived on-campus were more willing to take a DRR course than the students living off-campus, which might be because students living on-campus reside in university housing with very little 
access to essential supplies and no place for storage, which increases their vulnerability to a disaster [5]. Past research has indicated that students who perceive a higher risk of disasters tend to practice more disaster preparedness behaviour.

\subsection{Analysis of students' perceptions of disaster preparedness and education: Asian \& non-Asian students'}

The P-Values in Table 3 suggest that the students' perceptions of their personal role and that of their friends, parents, and the university in a disaster differ, based on their ethnicity (Asian and non-Asian). However, irrespective of their ethnicity, students have similar perspectives on the responsibility of government agencies for the safety of students' during an emergency. Asian and non-Asian students' have different perspectives on mandatory DRR education in educational institutions. It was revealed that there is a significant difference in the perceptions of students of different ethnic backgrounds on disaster medical knowledge provided in the curriculum. Moreover, it was found that Asian and non-Asian students have a different level of awareness of first aid boxes provided by the university. It was observed that Asian students were more aware of the medical supplies provided by the university than the non-Asian students.

\section{Conclusion}

In conclusion, it was observed that DRR education is perceived significantly differently by students who live on-campus and students who live off-campus. The same difference exists, based on their area of living and ethnicity, between the students' perceptions regarding mandatory disaster risk reduction education. Among the Asian and non-Asian students, there was a significant difference in awareness regarding medical supplies provided by the university. This is an interesting finding, as many Asian students in the U.S. universities are international students who are unfamiliar with university emergency procedures and local emergency management services. Furthermore, it was also revealed that both the area of living and ethnic background of students affected their perspectives regarding the roles of their friends, parents, and university in students' safety during a disaster. Students had similar perspectives of the government's role in their safety, irrespective of the area of living or ethnicity. The findings of this study will help policymakers implement changes in existing disaster preparedness programs and will help faculty members and the academic staff to effectively develop and implement disaster preparedness courses and drills at the university, based on different characteristics of the students.

\section{References}

[1] Rouhanizadeh B., Kermanshachi S. "Investigating the Relationships of Socioeconomic Factors Delaying Post-Disaster Reconstruction" ASCE International Conference on Computing in Civil Engineering, Atlanta, GA, June 17-19, 2019. https://doi.org/10.1061/9780784482445.005

[2] Pamidmimukkala A., Kermanshachi S. \& Safapour E. "Challenges in Post Disaster Housing Construction: Analysis of Urban Vs. Rural Communities" Creative Construction Conference, June 2020.

[3] Kermanshachi, S., Bergstrand, K. and Rouhanizadeh, B. "Identifying, Weighting and Causality Modeling of Social and Economic Barriers to Rapid Infrastructure Recovery from Natural Disasters: A Study of Hurricanes Harvey, Irma and Maria," Technical Report, U.S. Department of Transportation, C-TEDD, January 2019.

[4] Nipa T J., Kermanshachi S, and Ramaji I J. "Comparative Analysis of Strengths and Limitations of Infrastructure Resilience Measurement Methods". 7th CSCE International Construction Specialty Conference (ICSC), 2019.

[5] Nipa T H, and Kermanshachi S. Identification of the Resilience Dimensions and Determination of their Relationships in Critical Transportation Infrastructures. ASCE Construction Research Congress (CRC), 2019.

[6] Tan, Y., Liao, X., Su, H., Li, C., Xiang, J., \& Dong, Z. "Disaster preparedness among university students in Guangzhou, China: assessment of status and demand for disaster education." Disaster Medicine and Public Health Preparedness, 11(3), 310-317, 2017. https://doi.org/10.1017/dmp.2016.124

[7] Nahayo, L., Li, L., Habiyaremye, G., Richard, M., Mukanyandwi, V., Hakorimana, E., \& Mupenzi, C. "Extent of disaster courses delivery for the risk reduction in Rwanda." International Journal of Disaster Risk Reduction, 27, 127-132, 2018. https://doi.org/10.1016/j.ijdrr.2017.09.046

[8] Rouhanizadeh B, and Kermanshachi S. "A Systematic Approach to Analysis and Prioritization of the Socioeconomic Policies and Legal barriers to Rapid Post Disaster Reconstruction". 7th CSCE International Construction Specialty Conference (ICSC), 2019.

[9] Safapour E., Kermanshachi S. \& Nipa T. "Analysis of Cost Performance Indicators in Reconstruction Projects: A Comparative Study of Low Vs. High Level Damages" Creative Construction Conference, June 2020.

[10] Safapour E., Kermanshachi S. \& Nipa T. "Schedule Performance Analysis of Infrastructure Reconstruction Projects due to Extreme Events" Creative Construction Conference, June 2020.

[11] Kermanshachi, S., and B. Rouhanizadeh. Feasibility analysis of post-disaster reconstruction alternatives using automated BIM-based construction cost estimation tool. In Proceeding of CSCE 6th International Disaster Mitigation Specialty Conference, Montreal: Canadian Society of Civil Engineering, June 13-16, 2018.

[12] Safapour E., Kermanshachi S. \& Nipa T. "A Damage-Based Analysis of Rework in Reconstruction of Infrastructure Projects due to Natural Disasters" Creative Construction Conference, June 2020. 
[13] Pamidmimukkala A., Kermanshaci S. \& Kartick S. "Impact of Natural Disasters on Construction Projects: Strategies to Prevent Cost and Schedule Overruns in Reconstruction Projects" Creative Construction Conference, June 2020.

[14] Patel R., Kermanshachi S. \& Nipa T. "Establishment of a Framework to Measure Disaster Preparedness: Development of Strategies to Enhance Disaster Preparedness Activities" Creative Construction Conference, June 2020.

[15] Safapour E, and Kermanshachi S. "Investigation of the Challenges and Their Best Practices for Post-Disaster Reconstruction Safety: Educational Approach for Construction Hazards". Transportation Research Board 99th Annual Conference, 2019

[16] Nipa T., Kermanshachi, S. \& Patel R. "Impact of Family Income on Public's Disaster Preparedness and Adoption of DRR Courses" Creative Construction Conference, June 2020.

[17] Nipa T, J, Kermanshachi S, Patel R., Taffazoli M. "Disaster Preparedness Education: Construction Curriculum Requirements to Increase Students' Preparedness in Pre-and Post-Disaster Activities", Associated Schools of Construction (ASC) International Conference, 2020

[18] Jaradat, A., Mziu, H., \& Ibrahim, J. "Disaster preparedness in universities." Int Comput Trends Tech, 19(1), 1-4, 2015

[19] Tanner, A., Doberstein, B., "Emergency preparedness amongst university students." International Journal of Disaster Risk Reduction, 13, pp 409-413, 2015. https://doi.org/10.1016/j.jjdrr.2015.08.007

[20] Goddard, S., Sheppard, M., Thompson, K., Konecny, L, "Disaster preparedness knowledge." Beliefs, Risk-Per, 2018.

[21] Yusuf, S., \& Susanti, S. S. "Disaster preparedness in the red zone schools at 13 years post tsunami 2004." In IOP Conference Series: Earth and Environmental Science (Vol. 273, No. 1, p. 012038). IOP Publishing, 2019. https://doi.org/10.1088/1755-1315/273/1/012038

[22] Safapour, E., and Kermanshachi, S. (2020). "Identification and Categorization of Factors Affecting Duration of Post-Disaster Reconstruction of Interdependent Transportation Systems." Proceedings of ASCE Construction Research Congress (CRC), Arizona, US, March 8-10, 2020.

[23] Rouhanizadeh B, and Kermanshachi S. "Comparative Analysis of Public's and Decision-Maker's Perspectives on Socioeconomic Barriers Causing Delay in Post-disaster Recovery Processes". ASCE Construction Research Congress (CRC), 2019

[24] Rouhanizadeh B, Kermanshachi S and Dhamangaonkar V S. "Identification and Categorization of Policy and Legal Barriers to LongTerm Timely Post- Disaster Reconstruction". Journal of Legal Affairs and Dispute Resolution in Engineering and Construction, 2019. https://doi.org//10.1061/(ASCE)LA.1943-4170.0000307

[25] United Nations Office for Outer Space Affairs. Risk and Disasters. http://www.un-spider.org/risks-and-disasters

[26] Rouhanizadeh B and Kermanshachi S. "Gender-Based Evaluation of Physical, Social, and Economic Challenges in Natural Disasters Management". ASCE construction research congress (CRC), 2019

[27] Boustan, L. P., Kahn, M. E., Rhode, P. W., \& Yanguas, M. L. "The effect of natural disasters on economic activity in us counties: A century of data." National Bureau of Economic Research (No. w23410), 2017. https://doi.org/10.3386/w23410

[28] Coveleski, J. "A study of students' perception of natural disaster plans and emergency preparedness at a higher education institution". Master Thesis, Florida State University, 2014.

[29] Smalley A. "Higher education Responses to Coronavirus (Covid-19)" National Conference of State Legislatures, 06/15/2020 https://www.ncsl.org/research/education/higher-education-responses-to-coronavirus-covid-19.aspx

[30] United Nations Educational, Scientific and Cultural Organization (UNESCO) "Education: From disruption to recovery" https://en.unesco.org/covid19/educationresponse

[31] M. Namian, A. Albert, C. M. Zuluaga, and E. J. Jaselskis, "Improving Hazard-Recognition Performance and Safety Training Outcomes: Integrating Strategies for Training Transfer," Journal of Construction Engineering and Management, vol. 142, no. 10 , p. 04016048,2016 . https://doi.org/10.1061/(asce)co.1943-7862.0001160

[32] M. Namian, A. Albert, C. M. Zuluaga, and M. Behm, "Role of Safety Training: Impact on Hazard Recognition and Safety Risk Perception," Journal of Construction Engineering and Management, vol. 142, no. 12, p. 04016073,2016. https://doi.org/10.1061/(ASCE)CO.1943-7862.0001198

[33] Rouhanizadeh B, Kermanshachi S, and Nipa T J. "Identification, Categorization, and Weighting of Barriers to Timely Post-Disaster Recovery Process". ASCE International Conference on Computing in Civil Engineering, 2019. https://doi.org/10.1061/9780784482445.006

[34] Watson, P., Loffredo V., McKee J. “When a natural disaster occurs: Lessons learned in meeting students' needs”. J Prof Nurs 27: $362-$ 369, 2011. https://doi.org/10.1016/j.profnurs.2011.09.001

[35] A. Amri, K. R. Ronan, D. Bird and K. Haynes, "Disaster Risk Reduction Education in Indonesia Challenges and Recommendations for Scaling Up," Natural Hazards and Earth System Sciences, vol. 1, no. 1, pp. 1-8, 2016. https://doi.org/10.5194/nhess-2015-344

[36] Montgomery, D. C., \& Runger, G. C. "Applied statistics and probability for engineers". (3 ${ }^{\text {rd }}$ Edition), John Wiley \& Sons, 2003 